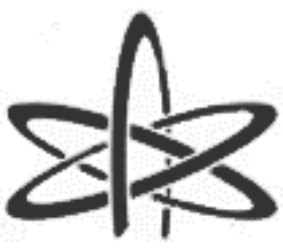

BJRS
BRAZILIAN JOURNAL

$\mathrm{OF}$

RADIATION SCIENCES

07-02A (2019) 01-11

\title{
Effect of the ohmic drop in a RPC-like chamber for measurements of electron transport parameters
}

\author{
A. R. Petri ${ }^{\mathrm{a}, \mathrm{b}}$; A. Mangiarotti ${ }^{\mathrm{b}}$; J. A. C. Gonçalves ${ }^{\mathrm{a}}$; C. C. Bueno ${ }^{\mathrm{a}}$ \\ ${ }^{a}$ Instituto de Pesquisas Energéticas e Nucleares (IPEN-CNEN/SP) \\ 05508-000 São Paulo, SP, Brazil \\ ccbueno@ipen.br \\ ${ }^{b}$ Instituto de Física - Universidade de São Paulo (IFUSP) \\ 05508-080, São Paulo, SP - Brazil
}

\begin{abstract}
The main advantage of Resistive Plate Chambers (RPCs), applied, for instance, in High-Energy Experiments and Positron Emission Tomography (PET), is that it is spark-protected due to the presence of, at least, one high-resistive electrode. However, the ohmic drop across the latter can affect the charge multiplication significantly. In this work, we investigate this effect in a RPC-like chamber. The counter was filled with nitrogen at atmospheric pressure and the primary ionization was produced by the incidence of nitrogen pulsed laser beam on an aluminum cathode. The illumination area of the cathode was measured using a foil of millimetric paper overlaid on this electrode. In this way, the resistance of the glass anode could be estimated using the known resistivity of the glass $\left(\rho=2 \times 10^{12} \Omega . \mathrm{cm}\right)$. Therefore, the voltage drop across the dielectric was calculated by the product of the current across the gas gap and the anode resistance. In order to mitigate the effect of the resistive electrode, the laser beam intensity was limited by interposing metallic meshes between the laser and the chamber window. The dependence of the ohmic drop from the applied voltage was analyzed. The results obtained shown that, without the meshes, the ohmic drop corresponds up to $7 \%$ of the applied voltage, preventing the detection system to reach values of density-normalized electric fields in the gas gap $\left(\mathrm{E}_{\text {eff }} / \mathrm{N}\right)$ higher than $166 \mathrm{Td}$. By minimizing the laser beam intensity and, consequently, the primary ionization, the ohmic drop represented only $0.2 \%$ of the applied voltage, extending the $E_{\text {eff }} / \mathrm{N}$ range up to $175 \mathrm{Td}$.
\end{abstract}


Keywords: electron transport parameters, RPC detectors, gaseous detectors.

\section{INTRODUCTION}

The successful application of Resistive Plate Chambers (RPCs) in High Energy Experiments, as both trigger and time-of-flight detectors, is due to the good time resolution, down to $50 \mathrm{ps}[1,2]$, coupled to their relatively low cost and simplicity of operation, which make these detectors suitable for covering large areas [3-5]. These characteristics also enable their use in Positron Emission Tomography (PET) with a performance comparable to scintillator detectors, but for a lower cost per channel $[2,6]$.

The main feature of RPCs is that at least one of the electrodes is made of high-resistivity material, such as glass or Bakelite, protecting the detector against spark-induced damages. The charge produced in gas avalanches is deposited onto the surface of the electrodes. This charge will create a voltage drop across the dielectric, decreasing the voltage across the gas gap and, consequently, the density-normalised electric field $(\mathrm{E} / \mathrm{N})$ in the gaseous medium. Usually, the density-normalised electric field is expressed in Townsend (Td) units, where $1 \mathrm{Td}=10^{-21} \mathrm{Vm}^{2}$. In the case of high-rate irradiation or a significant number of primary particles, the charge multiplication will be affected by this phenomenon, resulting in lower gas gain and efficiency. This effect depends on the current across the gas gap and the applied voltage, becoming significant with the rise of both.

In our three first papers on this topic [7-9], the effect of a resistive electrode was analysed employing a cylindrical glass tube divided in two sections, one with a conductive layer on the inner surface, acting as a metallic counter and the another one with the conductive layer on the outer surface, forming a resistive detector, providing the same experimental conditions. The difference in their behaviours was well explained by the ohmic drop across the resistive electrode in the avalanche mode [8].

In another previous work [10], a RPC-like counter was adopted, where the primary ionization was produced by the incidence of a pulsed nitrogen laser beam on an aluminium cathode and the anode was made of a high-resistivity glass. This setup was developed for determining electron transport parameters in gases which have been scarcely studied in terms of these quantities, such as isobutane [10-12] and tissue-equivalent gas mixtures [13]. The influence of secondary process (space charge, recombination and voltage drop) on the determination of the first Townsend ionization coefficient in 
pure isobutane was investigated under different laser pulse rates and laser beam intensities: the only one affecting significantly the results was the voltage drop.

In order to minimize the influence of the ohmic drop across the dielectric, we investigate further this phenomenon in the setup for the measurement of the electron transport parameters in gases, employed previously in [10], aiming to extend the range of the electric field so far covered by restricting the laser beam intensity.

\section{EXPERIMENTAL SETUP}

The full description of the experimental apparatus can be found elsewhere [10-13]. Briefly, the anode is made of a high-resistivity glass $\left(\rho=2 \times 10^{12} \Omega . \mathrm{cm}\right)$ with a thickness of $3.5 \mathrm{~mm}$ and an area of $32.5 \times 32.5 \mathrm{~mm}^{2}$. It is separated by $1.5 \mathrm{~mm}$ from a 40 -mm-diameter aluminum cathode. Both electrodes are connected with micrometers used for their adjustment. For the anode polarization, a high voltage supply (Bertan ${ }^{\circledR} 225-30 \mathrm{R}$, whose ripple is $0.002 \%$ ) was attached to a brass plate, glued on the glass anode. As filling gas, nitrogen was adopted here because it has been used as a reference gas in our previous works due to the extensive literature on its electron transport parameters and cross sections.

The primary ionization was produced by the grazing incidence of a pulsed nitrogen laser beam (MNL200-LD LTB $^{\circledR}$ ) onto the metallic cathode. The 700-ps laser pulse has a nominal energy of $100 \mu \mathrm{J}$ at $15 \mathrm{~Hz}$ repetition rate. The laser beam dimension is $1 \mathrm{~mm} \times 2 \mathrm{~mm}$, being projected on the cathode with an area of $3 \times 5 \mathrm{~mm}^{2}$, measured by covering the cathode with a thermal millimetric paper foil.

The integrated current in the gas gap was measured using a $6517 \mathrm{~B}$ Keithley ${ }^{\circledR}$ electrometer (accuracy of $1 \%$ of reading $+3 \mathrm{fA}$ for currents up to $20 \mathrm{pA}$ ) directly connected to the cathode. An average over 300 electric current readings was performed for each voltage (and, consequently, density-normalized electric field, E/N). In order to determine the noise current, 100 current readings were also measured with the laser beam on, but blocked by a shutter. In this way, the avalanche current $\left(\mathrm{I}_{\mathrm{n}}\right)$ was calculated as the difference between the mean value of the currents with and without the laser beam incident onto the cathode. $\mathrm{I}_{\mathrm{n}}$ represents the integrated current in the gas gap due to the phenomenon known as Townsend avalanche multiplication, where the primary electrons are accelerated towards the anode by the applied electric field, producing new ionizations.

The ohmic drop was determined from the product of $I_{n}$ and the glass anode resistance, estimated from the laser beam projection area and the known glass resistivity $\left(\rho=2 \times 10^{12} \Omega . \mathrm{cm}\right)$. The density- 
normalized electric field in the gas gap, named herein as effective reduced electric field $\left(E_{\text {eff }} / N\right)$, was calculated taking into account that the voltage across the gap is the applied one minus the ohmic drop. This means that, if the latter is significant, $E_{\text {eff }} / \mathrm{N}$ might keep constant even when the applied voltage increases, as observed in a previous paper with isobutane [10]. This results in a maximum value of $E_{\text {eff }} / \mathrm{N}$ lower than the possible one, considering the absence of this effect.

In order to minimize the ohmic drop, the avalanche current can be reduced by decreasing the laser beam intensity with metallic meshes interposed in its path. For each beam attenuation, the $I_{n}$ determination procedure was repeated with and without the laser beam passing through the mesh. The attenuation coefficient could thus be determined. Then, this coefficient was applied to the following currents measured with the mesh interposed in the laser path. In this way, it is possible to limit the current in the gap and hence the ohmic drop. These two methods of dealing with the ohmic drop: the one adopted in our previous works [10-12] of correcting for the calculated ohmic drop and the one employed here of limiting the ohmic drop by controlling the laser beam intensity, have been compared, in the present work, using measurements made with the chamber filled with pure nitrogen, a gas with well-established sets of data on both electron cross sections and transport parameters. As this setup is dedicated to determine the electron transport parameters, we also determine one of them, the first Townsend ionization coefficient, $\alpha$, as it is the core of our most recent works [10-13]. This parameter is calculated as $\alpha=\ln \left(\mathrm{I}_{\mathrm{n}} / \mathrm{I}_{0}\right) / \mathrm{d}$, where $\mathrm{d}$ is the gas gap $(1.5 \mathrm{~mm})$ and $\mathrm{I}_{0}$ is the primary ionization current, determined with the same procedure as $\mathrm{I}_{\mathrm{n}}$. However, in the case of $\mathrm{I}_{0}$, the E/N values are low enough to avoid electron multiplication in the gas.

A FP 2000 Honeywell ${ }^{\circledR}$ pressure transducer (0.25\% accuracy) was used to access the pressure inside the chamber. It was calibrated in the range of $0-1015 \mathrm{hPa}$ and connected with a MPL 1303M Minipa ${ }^{\circledR}$ DC power supply and a 289 Fluke $^{\circledR}$ multimeter. The temperature was registered with a RHT Extech ${ }^{\circledR}$ datalogger. All the measurements were carried out at atmospheric pressure $(930 \pm 2) \mathrm{hPa}$ and room temperature $(18 \pm 1)^{\circ} \mathrm{C}$. The overall uncertainty of $\alpha / \mathrm{N}$ experimental data was estimated in $15 \%$, as showed in Table 1. 
Table 1: Uncertainty budget of $\alpha / \mathrm{N}$

\begin{tabular}{ccc}
\hline Source of uncertainty & Type A & Type B \\
\hline Electric current & $\leq 5 \%$ & $1.0 \%$ \\
Standard desviation of the mean of $\mathrm{I}_{0}$ & $\leq 5 \%$ & ---- \\
Gas gap & --- & $0.05 \%$ \\
Temperature & $\leq 6 \%$ & $0.25 \%$ \\
Pressure - Honeywell $^{\circledR}$ & ---- & $0.6 \%$ \\
Pressure - Fluke $^{\circledR}$ & $\leq 0.12 \%$ & $0.05 \%$ \\
Ripple - Bertan $^{\circledR}$ & --- & $0.002 \%$ \\
Reproducibility & $\leq 12 \%$ & ---- \\
\hline Total per type & $15 \%$ & $1.2 \%$ \\
\hline TOTAL & \multicolumn{2}{c}{$\mathbf{1 5 \%}$} \\
\hline
\end{tabular}

\section{RESULTS AND DISCUSSIONS}

The ohmic drop across the resistive electrode, $\mathrm{dV}$, was calculated as described in the previous section for both the ionization (up to $100 \mathrm{Td}$ ) and avalanche multiplication regimes for each value of the applied voltage, $\mathrm{V}$, in the range of $1000-6200 \mathrm{~V}$. The relationship between $\mathrm{dV}$ and $\mathrm{V}$ is shown in Fig. 1, where the black squares represent the results obtained when the laser bean intensity was attenuated, preventing the increase of electric current intensity across the glass, and the red circles represent the results in the absence of this procedure, when the density-normalized electric field requires the correction for the ohmic drop effect. The uncertainty on $\mathrm{dV}$ was calculated considering both the instrumental and statistical ones and is lower than $2.2 \%$. The densitynormalized electric field intensities, E/N, corresponding to the applied voltages (i.e., without any correction for the ohmic drop), are also displayed. 
Figure 1: Ohmic drop, $d V$, across the glass anode as function of the applied voltage, $V$. The densitynormalized electric field, E/N, corresponding to the applied voltage, $V$, is also reported in the horizontal scale on the top of the figure.

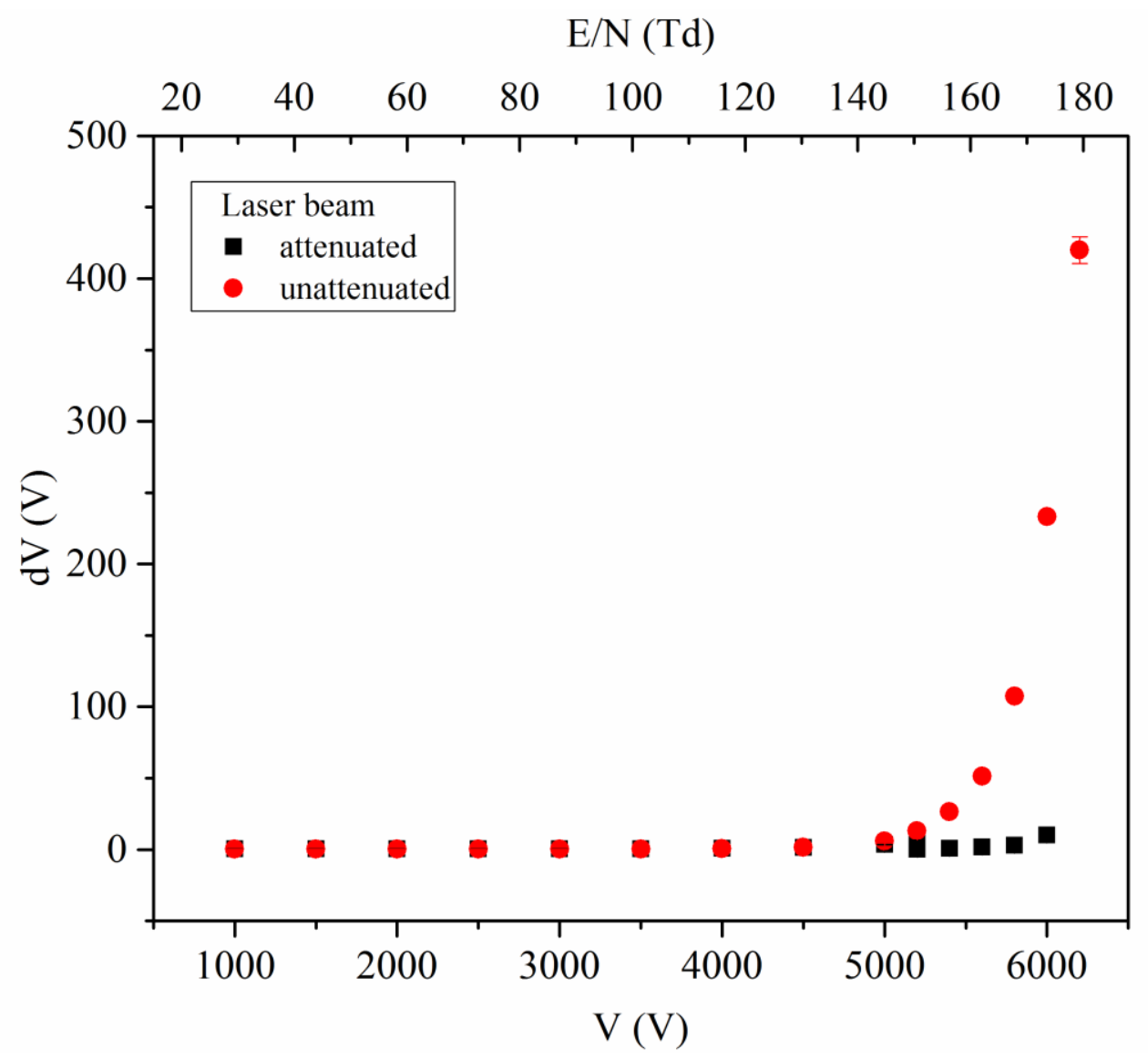

Keeping the laser beam intensity constant, the electric current intensity, and consequently the ohmic drop, is also steady throughout the ionization mode, only increasing in the proportional mode, due to the charge multiplication. Despite the increase of the ohmic drop in the latter regime, it becomes significant only above $5600 \mathrm{~V}(\mathrm{E} / \mathrm{N}=160 \mathrm{Td})$ when it is bigger than $1 \%$ of the applied voltage, reaching $7 \%$ at $6200 \mathrm{~V}$. Such values need to be corrected for. In terms of electric currents, this effect was significant above $10 \mathrm{pA}$, while the mean value of the primary ionization current was $(0.062 \pm 0.010) \mathrm{pA}$.

Reducing the laser beam intensity, the electric current was kept below $2.5 \mathrm{pA}$. Therefore, the ohmic drop represented up to $0.2 \%$ of the applied voltage, rendering negligible any correction. During ionization mode, the beam was not attenuated. Thus, the electric current behavior was similar to the one observed in the previous procedure.

The values of $\mathrm{E} / \mathrm{N}$ corrected for the effect of the ohmic drop, considering both methods are presented in Fig. 2 for the avalanche multiplication region. 
Figure 2: Density-normalized electric field corrected for the ohmic drop, $E_{\text {eff }} / N$, as function of $E / N$.

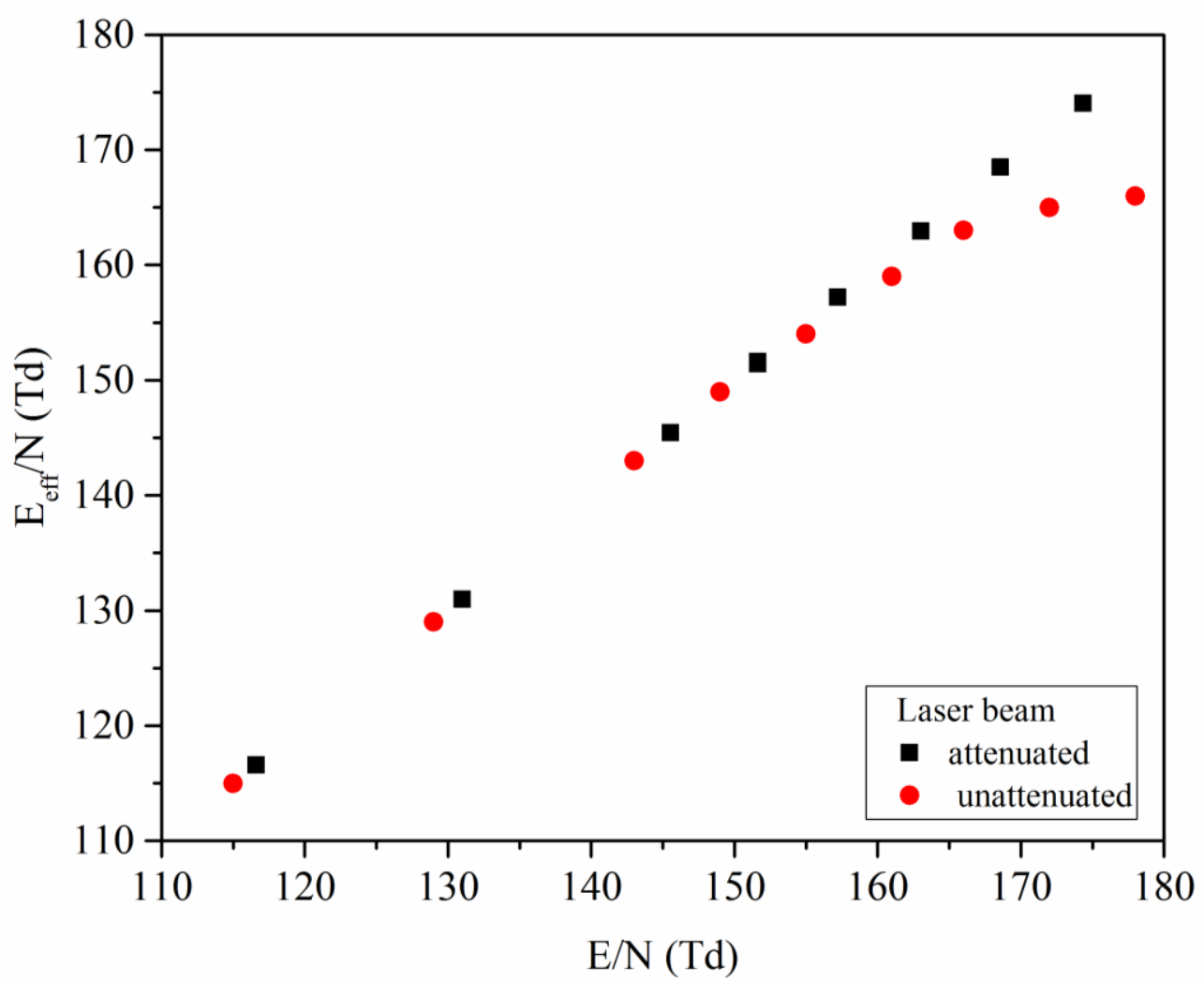

The relationship between $E_{\text {eff }} / \mathrm{N}$ e $\mathrm{E} / \mathrm{N}$ is linear, showing that the voltage loss in the dieletric is negligible, when the laser beam intensity is reduced with the increase of $\mathrm{V}$ and, consequently, no correction is needed. However, a significant deviation from the linear behavior is observed when the beam intensity is kept even. If the ohmic drop is high, the density-normalized electric field in the gas gap is reduced, resulting in a lower gas gain than the one obtained for the same experimental condition in the absence of this effect.

As mention before, the first Townsend ionization coefficient is a key quantity to describe the avalanche multiplication mode. For this reason, $\alpha$ normalized to the gas density, $\mathrm{N}$, was determined as a function of $E_{\text {eff }} / \mathrm{N}$ using both methods and compared with $\alpha / \mathrm{N}$ values simulated by Magboltz 2 version 8.6 [14-17]. This code was developed by S. Biagi to calculate electron transport parameters using Monte Carlo method. The label " $\mathrm{N}_{2} 2008$ " stands for a cross section set with "aniso 2" being the default option for the treatment of anisotropies. An extensive discussion about Magboltz 2 and its results for $\mathrm{N}_{2}$ has been published in our previous papers [12, 13] and will not be repeated here. 
For the sake of comparison, Fig. 3 also displays experimental data selected from the literature [1820].

Figure 3: Reduced first Townsend ionization coefficient as function of $E_{\text {eff }} / N$. The line represents simulated values using Magboltz 2.8.6 [14-17].

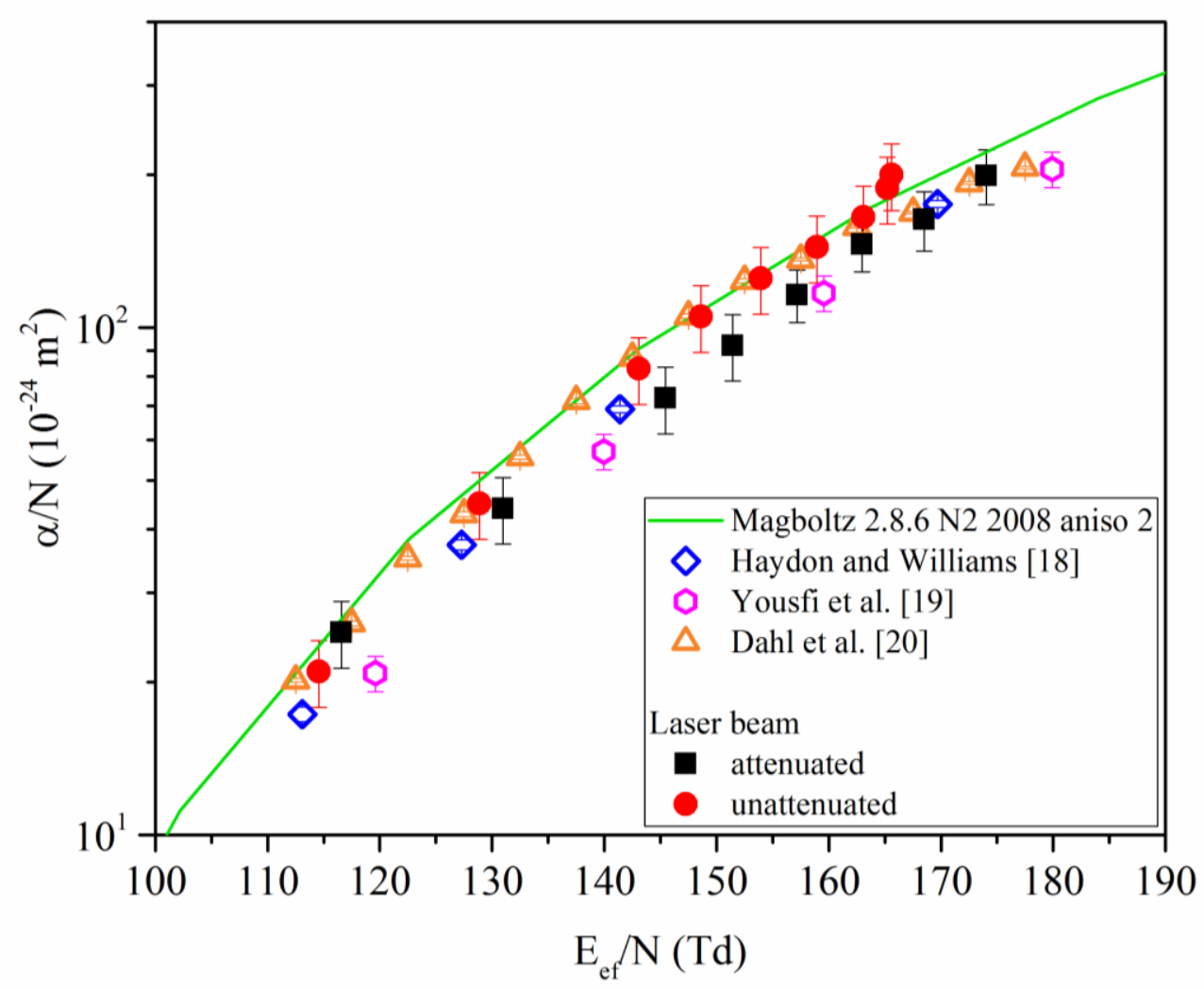

Considering the uncertainty bars, the present data sets are consistent, being also in agreement with results from other authors [18-20]. All experimental values of $\alpha / \mathrm{N}$ tend to be either in agreement with the curve calculated with Magboltz 2.8.6 or slightly lower than simulated results. Moreover, the presence of a strong ohmic drop limits the maximum value of the density-normalized electric field. By attenuating the laser beam, it was possible to reach a maximum applied voltage about 200 $\mathrm{V}$ bigger than with the unattenuated beam. Correspondingly, the $\mathrm{E}_{\mathrm{eff}} / \mathrm{N}$ reached higher values in the former case $(175 \mathrm{Td})$ : without using metallic meshes, the maximum $\mathrm{E}_{\mathrm{eff}} / \mathrm{N}$ was $166 \mathrm{Td}$, because of the voltage drop across the glass anode. 


\section{CONCLUSION}

A significant voltage loss in the glass anode, up to $7 \%$ of the applied voltage, prevented the measurement system to achieve values of effective density-normalized electric field higher than 166 $\mathrm{Td}$, when no attenuation of the laser beam was adopted. With the use of metallic meshes, the ohmic drop was reduced to $0.2 \%$ of applied voltage, extending the $\mathrm{E}_{\mathrm{eff}} / \mathrm{N}$ range up to $175 \mathrm{Td}$ and eliminating the need of corrections.

\section{ACKNOWLEDGMENT}

A. R. Petri would like to thank CNPq for the award of a scholarship. This work was co-financed by FAPESP (contract 02/04697-1) and by CNPq (contracts 478859/2009-0 and 479079/2010-2).

\section{REFERENCES}

1. FONTE, P. High-resolution timing of MIPs with RPCs - a model. Nuclear Instruments and Methods in Physics Research A, v. 456, p. 6-10, 2000.

2. BELli, G.; GABUSI, M.; MUSITELli, G.; NARDÒ, R.; RATTI, S. P.; TAMBORINI, A.; VITULO, P. Multigap RPC time resolution to $511 \mathrm{keV}$ annihilation photons. Nuclear Instruments and Methods in Physics Research A, v. 781, p. 26-33, 2015.

3. AKINDINOV, A.; DREYER, J.; FAN, X.; KÄMPFER, B.; KISELEV, S.; LASO GARCIA, A.; MALKEVICH, D.; NAUMANN, L.; NEDOSEKIN, A.; PLOTNIKOV, V.; DTACH, D.; SULTANOV, R.; VOLOSHIN, K. Radiation-hard ceramic Resistive Plate Chamber for forward TOF and TO systems. Nuclear Instruments and Methods in Physics Research A, v. 845, p. 203-205, 2017

4. BHATT, A. D.; MAJUMDER, N. K. MONDAL, PATHALESWAR, SATYANARAYANA, B.; Improvement of time resolution in large area single gap Resistive Plate Chambers. Nuclear Instruments and Methods in Physics Research A, v. 844, p. 53-61 (2017).

5. HADDAD, Y.; LAKTINEH, I.; GRENIER, G.; LUMB, N.; CAUWENBERGH, S. High rate resistive plate chamber for LHC detector upgrades. Nuclear Instruments and Methods in Physics Research A, v. 718, p. 424-426, 2013. 
6. BLANCO, A.; FONTE, P.; LOPES, L.; MANGIAROTTI, A.; FERREIRA MARQUES, R.; POLICARPO, A. Resistive plate chambers for time-of -flight measurements. Nuclear Instruments and Methods in Physics Research A, v. 513, p. 8-12, 2003.

7. BUENO, C. C.; FRAGA, M. M.; GONÇALVES, J. A. C.; FERREIRA MARQUES, R.; POLICARPO, A. J. P. L.; SANTOS, M. D. S. Rate effects in a proportional counter with resistive cathode. Nuclear Instruments and Methods in Physics Research A, v. 408, p. 496$502,1998$.

8. FRAGA, M. M.; DE LIMA, E. P.; FERREIRA MARQUES, R.; POLICARPO, A. J. P. L.; BUENO, C. C.; GONÇALVES, J. A. C.; SANTOS, M. D. S. Rate effects in radiation detectors with resistive electrodes. IEEE transactions on Nuclear Science, v. 45, p. 263-268, 1998.

9. FRAGA, M. M.; FERREIRA MARQUES, R.; IVANIOUCHENKOV, Y.; DE LIMA, E. P.; NEVES, F.; POLICARPO, A. J. P. L.; BUENO, C. C.; GONÇALVES, J. A. C.; SANTOS, M. D. S.; COSTA, L.; MENDIRATTA, S.; MONTEIRO, J. H. Transient behaviour and rate effects in resistive detectors. Nuclear Instruments and Methods in Physics Research A, v. 419, p. 485-489, 1998.

10. MANGIAROTTI, A.; LIMA, I. B.; VIVALDINI, T. C.; GONÇALVES, J. A. C.; PETRI, A. R.; BOTELHO, S.; FONTE, P.; BUENO, C. C. Secondary effects on electron multiplication in pure isobutene. Nuclear Instruments and Methods in Physics Research A, v. 694, p. 162-166, 2012.

11. FONTE, P.; MANGIAROTTI, A.; BOTELHO, S.; GONÇALVES, J. A. C.; RIDENTI, M. A.; BUENO, C. C. A dedicated setup for the measurement of the electron transport parameters. Nuclear Instruments and Methods in Physics Research A, v. 613, p. 40-45, 2010.

12. LIMA, I. B.; MANGIAROTTI, A.; VIVALDINI, T. C.; GONÇALVES, J. A. C.; BOTELHO, S.; FONTE, P.; TAKAHASHI, J.; BUENO, C. C. Experimental investigations on the first Townsend coefficient in pure isobutene. Nuclear Instruments and Methods in Physics Research A, v. 670, p. 55-60, 2012.

13. PETRI, A. R.; GONÇAlVES, J. A. C.; MANGIAROTTI, A.; BOTElHO, S.; BUENO, C. C. Measurement of the first Townsend ionization coefficient in a methane-based tissue-equivalent gas. Nuclear Instruments and Methods in Physics Research A, v. 849, p. 31-40, 2017.

14. BIAGI, S. Accurate solution of the Boltzmann transport equation. Nuclear Instruments and Methods A, v. 273, p. 533-535, 1988. 
15. BIAGI, S. A multiterm Boltzmann analysis of drift velocity, diffusion, gain and magnetic-field effects in argon-methane-water-vapour mixtures. Nuclear Instruments and Methods in Physics Research A, v. 283, p. 716-722, 1989.

16. BIAGI, S. Monte Carlo simulation of electron drift and diffusion in counting gases under the influence of electric and magnetic fields. Nuclear Instruments and Methods in Physics Research A, v. 421, p. 234-240, 1999.

17. BIAGI, S. Magboltz transport of electrons in gas mixtures. 1995. Available at: http://magboltz.web.cern.ch/magboltz/. Last accessed 20 may 2017.

18. HAYDON, S. C.; WILLIAMS, O. M. Combined spatial and temporal studies of ionization growth in nitrogen. Journal of Physics D: Applied Physics, v. 9, p.523-536, 1976.

19. YOUSFI, M.; DE URQUIJO, J.; JUÁREZ, A.; BASURTO, E.; HERNÁNDEZ-ÁVILA, J. L. Electron Swarm Coefficients in $\mathrm{CO}_{2}-\mathrm{N}_{2}$ and $\mathrm{CO}_{2}-\mathrm{O}_{2}$ Mixtures. IEEE Transactions on Plasma Science, v. 37, p. 764-772, 2009.

20. DAHL, D. A.; TEICH, T. H.; FRANCK, C. M. Obtaining precise electron swarm parameters from a pulsed Townsend setup. Journal of Physics D: Applied Physics, v. 45, p. 485201, 2012. 